\section{Análise de um documento: "Hunger in America": the growing epidemic"}

\author{
Physician Task Force on Hunger \\ in America. Harvard University, School of Public Health, \\ Boston, USA. 1985. * J. Larry Brown. *
}

\author{
* "Médicos denunciam que \\ fome já afeta 20 milhoes de \\ americanos". Noticia referente a \\ esta monografia publicada em \\ $O$ GLOBO, 27.02.85. \\ * Presidente da Força Tarefa.
}

Frederico Simões Barbosa Escola Nacional de Saúde Pública - FIOCRUZ, RJ.

\section{* Ver comentário de Paulo Sabroza}

As principais conclusões dos estudos, encabeçados pelo presidente do grupo-tarefa que conduziu a pesquisa, Prof. J. Larry Brown, identificaram uma série de problemas de saúde e de fome que não se poderiam imaginar num país do poder econômico dos EUA.

Em 1967 visitei a região dos Apalaches, logo após a publicação do famoso livro "Poverty in the United States", e verifiquei o baixo nível de vida daquela população vivendo num dos chamados "bolsões de pobreza" existentes no país.

Hoje, segundo os autores dessa monografia, a situação é muito pior.

As principais conclusões desse livro, ao mesmo tempo pungente e realista, são as seguintes:

- A fome é um problema de proporções epidêmicas, largamente distribuída no país e não mais nos "bolsões de pobreza", documentada em 15 estudos a nível nacional. Embora não se saiba exatamente o número de norte-americanos famintos, calcula-se que cerca de 20 milhões de cidadãos estiveram famintos pelo menos em algum período de cada mês. 


\section{*Mississippi Food Network Jackson, Mississippi}

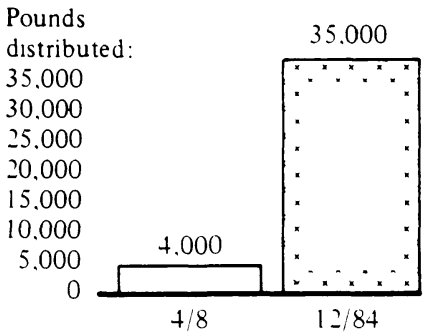

Source: Food Network records

*Programas como "Ajuda a Familias com Crianças Dependentes" (AFCD),

"Medicaid", têm notórias deficiências e cobertura inadequada.

**Em média, variam entre US\$ 91, em Mississippi, a US\$289, em Illinois.

** Percent loss in maximum AFDC benefits for four-person families in constant dollars (1970-1984).

$\begin{array}{ll}\text { Alabama } & 32.1 \% \\ \text { Mississippi } & 35.9 \\ \text { Tennessee } & 51.3 \\ \text { N. Carolina } & 47.7 \\ \text { New Mexico } & 35.7 \\ \text { Texas } & 58.0 \\ \text { Illinois } & 51.2 \\ \text { Missouri } & 11.4\end{array}$

Source:

Congressional Research Service 360
- O problema da fome tem piorado nos EUA, embora se possa pensar o contrário. Os programas emergenciais de alimentação, através do país, têm evidenciado o aumento de pessoas famintas. A demanda desses programas tem aumentado. Assim é que, no exemplo citado pelos autores para a localidade de Jackson, Mississipi, a demanda aumentou $300 \%$ de 1981 a $1984^{*}$.

- Desnutrição e doença estão associadas com a fome. Grupos populacionais vulneráveis, particularmente crianças e velhos, aumentaram o risco de adoecer. Os desnutridos chegam a perto de meio milhão de crianças norte-americanas. Os autores comentam que não é fácil correlacionar desnutrição e pobreza com doença. Consideram, entretanto, que os fatos que se seguem são muito claros:

- crianças de mães pobres morrem mais freqüentemente;

- crianças pobres, como grupo, têm menos chances de receber alimentação adequada e estão mais sujeitas a retardamento do crescimento;

- crianças pobres têm mais risco de morrer de desnutrição associada a doença relacionada, incluindo-se aqui marasmo e kwashiorkor;

adultos com baixos salários têm maior risco de contrair determinadas doenças relacionadas com a desnutrição e de morrer em idade mais jovem que os demais americanos.

- A fome é o resultado das políticas do governo federal, algumas delas surgidas nos últimos anos e outras de maior duração. Embora possam haver várias interpretações para o que os autores chamam "... return of hunger to America..." (alguns se chocam, outros são complacentes), a "... evidence is compelling that the hunger epidemic facing our nation today is largerly the result of policy decisions - some recent, some made during the past decade or earlier". A cuidadosa análise dos autores é feita levando em consideração os seguintes fatores: fraqueza da rede assistencial; grupos raciais vulneráveis ${ }^{*}$; impacto da recessão, com o crescente aumento da pobreza e do desemprego; e, finalmente, os cortes nos programas federais de nutrição e de salários ao desempregado, no momento em que os dois fatores acima atingiam o maior impacto. Os benefícios são baixos ${ }^{* *}$ e não-abrangentes. Tem havido perda substancial do salário de americanos pobres: a erosão do salário foi, em média, da ordem de $33 \%$, entre 1970 e 1984 . O orçamento federal e as políticas de taxação a partir de 1980 fizeram “... the plight of the poor worse while their suffering was greatested".*** Durante o período de 1975 a 1981, o país sofreu as mais elevadas taxas de inflação, sendo a mais baixa 10,4\%, em 1981, e

Cadernos de Saúde Pública, R.J., 1(3): 359-371, jul/set, 1985. 
a mais alta $13,5 \%$, em 1980 . Embora a inflação tenha baixado a $3.4 \%$, em média, o poder de compra das familias americanas de médio e baixo salários permaneceu virtualmente inalterado. O desemprego elevou-se de $6.2 \%$, no início de 1980 , a $10.7 \%$, ao final de 1982 . Atualmente, existem perto de 473.000 pessoas desempregadas. Enquanto o desemprego permanece a seus níveis mais elevados, a proporção de trabalhadores que recebe os benefícios do desemprego diminui. Em 1975, durante a recessão, quando o desemprego estava no mesmo nível atual, $78 \%$ dos americanos desempregados recebiam o seguro-desemprego. Esta proporção é atualmente de $39 \%$. De acordo com o "Congregacional Budget Office", o impacto cumulativo do orçamento e mais os cortes nos impostos resultaram na transferência de recursos dos mais pobres para os que tinham salário mensal acima de US\$80.000. Esta transferência é da ordem que se vê no gráfico ao lado.*

- As políticas atuais não estão melhorando o problema de fome nos EUA. A pobreza no país chegou ao mais alto nível destes últimos vinte anos, e o poder de compra dos mais pobres ( $40 \%$ da população) é mais baixo hoje do que em 1980. É pouco provável que a melhoria econômica dos mais ricos possa dar assistência aos que têm fome. $\mathrm{O}$ documento incrimina as políticas federais do governo americano como diretamente relacionadas com o substancial aumento da pobreza do povo americano. ${ }^{* *}$ Um em cada sete americanos vive em pobreza. Este dado, válido para o início de 1984, é o mais elevado índice de pobreza para os EUA desde 1965. A partir de 1980, a pobreza nesse país aumentou em $25.5 \%$. Outros dados, específicos para diferentes grupos de população, mostram aspectos aterradores da realidade americana. A pobreza atingiu duramente os lares americanos chefiados por mulheres não-brancas, cujo índice de pobreza chega a $70-80 \%$. As crianças são o grupo mais pobre, no momento, da população americana, entre os grupos mais vulneráveis: um em cada seis é pobre. Este índice dobra (2/5), quando é aplicado às crianças de origem hispânica. A discriminação racial continua a dividir o país em dois, o dos brancos e o dos não-brancos. Veja-se, ao lado, o exemplo dado pelos autores sobre o peso-ao-nascer em Davidson, área metropolitana de Nashville*. Embora tenha havido aumento em ambos os grupos, as diferenças entre eles são muito grandes. No Hospital Geral de Nashville, os indices são alarmantes para um país como os EUA**. Dados oficiais mostram que mulheres americanas negras têm probabilidade três vezes mais al ta do que as mulheres brancas de morrer por causas associadas à gravidez, parto e puerpério. $\mathrm{O}$ coeficiente da mortalidade infantil das crianças negras foi quase o dobro do das crianças brancas, em 1982,

\section{*Percentage change in real disposable income for U.S. families, 1980-84.}

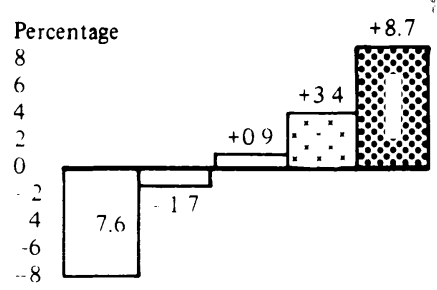

**Increasing tax burden on families of four with poverty-level income, 1978-1984.

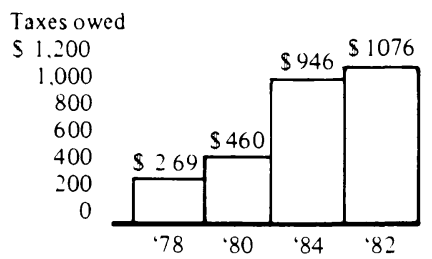

*Davidson County (Metropolitan Nashville) low birth-weight rates

$\begin{array}{cccc} & \text { Total } & \text { White } & \text { Non-white } \\ 1983 & 9.4 & 7.4 & 14.2 \\ 1982 & 8.8 & 7.0 & 13.1 \\ 1981 & 8.5 & 6.7 & 12.7\end{array}$

Metropolitan Nashville General Hospital (low birth-weight rates) -1981 -

$\begin{array}{llcc} & \text { Total } & \text { White } & \text { Non-white } \\ 1981 & 13.5 & 12.9 & 14.4\end{array}$

Sources: State Center for Health Statistics: Tennessee Department of Health and Environment, Metropolitan Nashville General Hospital.

\section{${ }^{*}$ A titulo de} comparação, menciona-se que peso-baixo-ao-nascer das crianças de Manguinhos, nesta cidade, é de 9,8\% (dados da U.T.G.S.F. (ENSP, 1984). 
***Bol. Epid., tal como se observa há 20 anos. *** Diversos fatores converOPS, 6:10-11, 1985. gem, durante os últimos anos, para agravar as condições de vida das famílias americanas, como mencionado anteriormente. O agravo econômico chegou a um nível sem par desde a Grande Depressão. A partir de 1981 (ano fiscal), as modificações nas leis e regulamentos governamentais alteraram os padrões de ilegibilidade e os níveis de benefício para os programas assistenciais de responsabilidade do governo federal. $\mathrm{O}$ resultado dessas modificações na legislação tomou muitos americanos recém-empobrecidos inelegíveis para assistência. Muitos dos que eram/assistidos tiveram seus benefícios cortados substancialmente, exatamente no momento em que suas necessidades cresciam.

Entraves burocráticos para dificultar o acesso às fontes de benefícios, fraude e abuso em programas governamentais são citados por pessoas entrevistadas e comprovados pelos autores.

O último capítulo desse documento "Eliminating hunger in America" representa um doloroso grito de responsabilidade profissional. Seus autores afirmam: "As a body of doctors and health care professionals, we believe it is time to end hunger in America* ${ }^{*}$. Mais adiante, afirmam que a fome e as doenças relacionadas não podem ter lugar numa sociedade democrática, especialmente com os recursos dos EUA, o país com, talvez, a economia mais forte do mundo.

Os autores assinalam que a fome no país foi detectada em 1968, afirmando, entretanto, que a nação respondeu ao problema estendendo, na década de 1970-1980, o programa de ajuda alimentar ("food-stamps") de dois milhões de beneficiários, no início, a vinte milhões de americanos pobres. Embora este programa não chegasse a cobrir toda a população carente, outros programas, como merenda escolar, alimentação para idosos e mães e crianças de alto risco, foram suficientes para responder ao desafio. Em poucos anos "this nation basically eliminated hunger as a problem". Hoje, dizem os autores, temos de fazer face a uma crise da saúde pública. Temos de responder a ela como faríamos a qualquer outro problema de proporçōes epidêmicas. "It is time to show more compassion for hungry families. .'

Nesse capítulo final, os Autores propõem medidas imediatas para resolver o problema. O libelo é endereçado ao Congresso Americano, em termos candentes mas vigorosos. As medidas propostas, todas assistenciais, são as seguintes:

reforçar o programa alimentar ("food-stamp");

reforçar a merenda escolar e outros programas alimentares para crianças;

utilizar o programa de alimentação de mulheres e 
crianças (WIC) mais efetivamente, a fim de proteger as crianças de al to-risco;

estender os benefícios de "Medicaid" a todas as mulheres grávidas e crianças abaixo de 18 anos vivendo abaixo do nível de pobreza;

expandir o programa alimentar para os idosos;

atender os benefícios do desemprego a todas as famílias desempregadas, que, no momento, representam dois terços não assistidos;

expandir os programas de assistência à criança de modo que se possa elevá-la acima do nível de pobreza.

No âmbito do poder legislativo, os autores solicitam ao Congresso a criação de um Comitê permanente e independente, com a finalidade de monitorizar o estado nutricional da população.

Como medidas a longo prazo, os autores preconizam ações mais sérias e de longo alcance para eliminar a pobreza no país, acreditando que o problema pode ser erradicado. Pedem ao Congresso dos Estados Unidos para criar uma Comissão Bipartidária de Estudos que venha a recomendar modificações legislativas, para proteger, no futuro, todos os nossos cidadãos das devastações da fome e das doenças relacionadas.

$\mathrm{O}$ apelo dos profissionais americanos é vago, não indicando quais as medidas legislativas a tomar. Se o problema subjacente da pobreza e da fome está (como parece implícito em vários trechos do documento) ligado à má distribuição da renda nacional, as modificações a operar terão de atingir profundamente as raízes estruturais da economia do pais.

Alguns podem interpretar estes dados como inevitável tragédia burguesa da conjuntura atual dos EUA que será corrigida com o tempo e o idealismo do povo americano. Outros, uma minoria, sem dúvida, como inaceitável distorção estrutural nos campos sociais, econômico e político do país.

Renato Pompeu*, citando três recentes livros americanos sobre a era Reagan, diz que ... "embora mundialmente os Estados Unidos guardem ainda a antiga imagem de campeões do liberalismo político, social e comportamental, na verdade essa imagem não corresponde mais à realidade interna da nação mais poderosa do mundo. O que essa leitura deixa claro é que a imagem do liberalismo, que mostra o "american way of life" como o máximo de liberação liberação sexual, direitos humanos, liberação da mulher, liberação homossexual, liberação do negro - corresponde na verdade a apenas um setor da população americana que já teve o poder na mão, criou durante décadas a identidade

Cadernos de Saúde Pública, R.J., 1 (3): 359-371, jul/set, 1985.
* $O$ povo americano procura sua alma perdida.

Folha de São Paulo, 22 de julho de 1985.

Livros citados:

T.H. White. Os Estados Unidos em busca de si mesmos - como foram feitos os presidentes de 1956 a 1980. Editado em inglês pela Harper \& Row.

K. Phillips. Os Estados Unidos pós-conservadores. Editado em inglês pela Vintage.

B. Gross. $O$ fascismo amigável. Editado em inglês pela Evans. 
Sérgio Koifman

Escola Nacional de Saúde Pública - FIOCRUZ-RJ. nacional americana - mas agora está irresistivelmente decadente".

Os mais novos ficcionistas americanos, representantes do pós-modernismo literário, revelam que o realismo de décadas passadas perdeu a credibilidade. Em seu lugar, surge a nova literatura da exaustão, uma metaficção, ligada à superação de dogmas e de regras. Será essa literatura o sinal da decadência da sociedade de consumo em sua forma dita mais avançada, a era pós-industrial?

Segundo o bem documentado trabalho "Fome na América, A Epidemia em Crescimento", torna-se dia-a-dia obsoleta a imagem de que a pobreza, para não mencionarmos a fome, era um atributo de certos grupos "minoritários" norte-americanos: negros, latinos e indígenas. Assim, o conceito conservador de WASP (iniciais na lingua inglesa de branco, anglo-saxão e protestante) vem perdendo seu poder de diferenciação quanto à caracterização dos grupos sociais mais elitizados, do ponto de vista da distribuição das riquezas.

Mediante uma ampla e diversificada coleta de dados obtidos através de entrevistas, análise de dados epidemiológicos e indicadores sócio-econômicos, os autores demonstram de maneira incontestável que o problema da fome atinge não somente as comunidades de todas as regiões geográficas do país, como, principalmente, é um fenômeno em expansão.

Ao contrário dos fenômenos agudos de carência alimentar, como aqueles observados na Europa ocupada durante a 2. Guerra ${ }^{1},{ }^{2}, 3,5$, aqui a fome apresenta-se de forma insidiosa, mascarando suas facetas mais agressivas e tão conhecidas dos países subdesenvolvidos. Embora casos de Kwashiorkor sejam crescentes, segundo os autores, em comunidades mais pobres como as reservas indígenas, a fome ou a preocupação com esta é que trazem indicadores seguros de sua existência. Em um dos estudos mencionados, um grupo de pesquisadores de Chicago que investigavam maltratos na infância descobriu, ao acaso, um elevado número de casos de super-hidratação (intoxicação pela água) em crianças de família de baixa renda, devido ao consumo de fórmulas lácteas extremamente diluídas, com o objetivo de aumentar o rendimento do leite concomitante à supressão dos sintomas superficiais da fome.

Outro indicador é que, durante 1984 , a procura por refeições distribuídas em entidades filantrópicas e sociais cresceu em todo o país, em relação a 1983, à ordem de $50 \%$, elevando-se com maior proporção em certas áreas: $180 \%$ em Chicago, $200 \%$ em Boston e $1000 \%$ em Houston, paralela- 
mente à diminuição do poder aquisitivo de seus estratos de menor renda.

Segundo estimativas dos autores, ao redor de vinte milhões de americanos passam fome pelo menos algum período de tempo durante todos os meses, e em número crescente: de acordo com padrões locais utilizados na definição de pobreza, havia 26 milhões nesta condição em 1979 e 35 milhões em 1983. O maior grupo destes é constituído por crianças, ao redor de $40 \%$, uma em cada duas crianças negras, duas em cada cinco de origem latina, "crianças que nunca comeram frutas e vegetais"! Surpreendente, em se tratando de uma nação com intensiva mecanização agrícola e "uma produção suficiente para alimentar a si própria e a boa parte do mundo".

Entre os indicadores de saúde mais conhecidos, a mortalidade infantil é um dos que reflete com maior precisão as modificações das condições de vida da população, particularmente devido a sua relação com os agravos durante o período pós-neonatal.

Neste sentido, é de grande interesse o seu acompanhamento, particularmente em situações de deterioração do poder aquisitivo, como evidenciado no trabalho realizado por Leser, em São Paulo, durante a década de $1970 .^{4}$

Nos EUA, a mortalidade infantil aumentou de 1981 para 1982 em dez estados e, se considerada a população nãobranca, minoritária na participação da riqueza, em treze; no bairro negro do Harlem, Nova York, ela foi da ordem de 25.6/1000 nascidos vivos, e 29.7 em Pittsburg, durante 1982 (22.8 em 1981), aumentando $46 \%$ entre os mesmos anos em Boston. Em termos de comparação, estas taxas são muito próximas àquela atualmente existente no Município do Rio de Janeiro (27.0), superiores à taxa cubana (15.0) ou quase quatro vezes maiores que as verificadas na Europa Ocidental (Holanda, Suécia, Dinamarca e outros países).*

Desde o clássico trabalho de Antonov, ${ }^{2}$ durante o cerco de Leningrado em 1942, quando a fome massiva provocou um decréscimo no peso médio ao nascer da ordem de $500 \mathrm{gr}$, o baixo peso ao nascer tem sido considerado outro indicador de grande sensibilidade para discriminar a prova das condições sociais de existência. Sua determinação é constatada através da inadequação daquela variável antropométrica com os valores esperados para o período de evolução gestacional ao momento do parto, ou mais amiúde, nas crianças com peso ao nascer menor que 2500 gr. Embora influenciadas por outras variáveis, tais como fumo, idade da mãe, paridade, período intergestacional, abortamentos prévios e outras, o ganho de peso da gestante, particularmente durante $o$ terceiro trimestre da gravidez, desempenha um papel decisivo na condição a baixo peso ao nascer; daí a
* WHO. World Health Statistics, 1983 e 1984, para as taxas européias; Divisão de Epidemiologia, Departamento Geral de Saúde Pública, Secretaria Municipal de Saúde para a taxa do Rio de Janeiro; e Dr. Jordan, Academia Cubana de Ciências, informe em conferência realizada no Rio de Janeiro. 
grande labilidade desta variável nas condições de restrição alimentar da gestante.

A influência de fatores genéticos na determinação do baixo peso ao nascer, embora eventualmente mencionada, não parece apresentar qualquer sustentação científica, uma vez que gestantes de diferentes grupos etários, com elevado padrão de consumo alimentar, apresentam distribuição de baixo peso ao nascer que não costuma superar a faixa de $5 \%$. Assim, o baixo peso ao nascer é considerado como mais um dos matizes em que a fome se materializa nos grupamentos humanos.

Neste estudo, os autores puderam observar, durante 1982, uma prevalência de baixo peso ao nascer da ordem de $5.6 \%$, em crianças brancas, e de $12.4 \%$, em crianças negras; no Harlem, bairro negro de Nova York, ela foi de $16.3 \%$. Por outro lado, a razão de baixo peso ao nascer em negros sobre brancos vem aumentando, de 2.03 em 1970 para 2.19 em 1981, evidenciando o empobrecimento relativo daqueles grupos populacionais.

Alguns inquéritos antropométricos realizados em diversos estados têm também revelado resultados compatíveis com este quadro de desnutrição. Embora alguns tenham sido realizados com a demanda de centros hospitalares, o que por si só indica a limitação em termos de representatividade destes grupos com a população geral, seus resultados são, de qualquer forma, interessantes de serem analisados, com a cautela devida, em função da possível tendenciosidade já mencionada.

Em um levantamento realizado em 5 mil crianças de Jackson, Mississippi, 70\% apresentavam hipovitaminose A e C, e $45 \%$ deficiência de ferro. Em outro estudo no Boston City Hospital, de 413 crianças, a metade das quais menores de seis anos, observou-se que $15 \%$ encontravam-se abaixo do percentil 5 da curva de peso para altura. Resultados semelhantes foram encontrados em outros locais, como no Cook County Hospital, onde $30 \%$ das crianças apresentavam seus valores de peso para idade abaixo do percentil 10 .

Inquéritos nutricionais com base populacional mostraram resultados na mesma direção: em Illinois, $17 \%$ das crianças menores de 1 ano e de baixa renda estavam aquém da curva de altura para idade; em Massachusetts, $18 \%$ das crianças tinham manifestações de deficiência nutricional crônica (1983); e, no Novo México, uma investigação abrangendo $18 \mathrm{mil}$ crianças e mulheres revelou deficiência de peso em $23 \%$ das crianças, e de $36 \%$ em altura (1984). Em base a estes resultados, estima-se que $500 \mathrm{mil}$ crianças apresentam retardo de crescimento e outros problemas relacionados a dieta deficiente. 
Este amplo espectro da fome atingindo diferentes grupos sociais e faixas etárias nos Estados Unidos teve também seus determinantes analisados detalhadamente pelos autores.

Tanto as análises estatísticas assinaladas, como as várias entrevistas apresentadas apontam para a esfera das políticas sociais como as principais implicadas no quadro atual da fome nos EUA, as quais foram recentemente debilitadas no governo Reagan. Por outro lado, as alterações introduzidas no sistema de saúde Medicare e Medicaid, aumentando os custos da atenção e diminuindo os recursos para as agências locais de saúde, acabaram por restringir o acesso dos grupos de baixa renda a estes serviços.

Os efeitos da recessão (o desemprego aumentou de $6.2 \%$ em 1980 para $10.7 \%$ em 1982 , embora diminuísse para 7.2\% em dezembro de 1984), paralelamente a uma política tributária privilegiando o Capital - "enquanto as taxações nas pessoas físicas cresceram de $73.5 \%$ para $82.9 \%$, entre $1970-83$, os tributos nas empresas durante o mesmo período decresceram de 15 para $6.2 \%$-, criaram o pano de fundo para o drama tão conhecido nosso da fome.

Para concluir, parece-nos importante mencionar a postura adotada pelos autores, válida para todos os povos que ainda enfrentam o mesmo problema: "uma resposta apropriada à fome na América converte-se em uma questão preferencialmente política, que da ciência; ela está para ser resolvida pela sociedade e não pelos pesquisadores".

\section{REFERÊNCIAS BIBLIOGRĀFICAS}

1. ADELSBERGER, L. Medical observations in Auschwitz concentration camp. Lancet, 1: 317-9, Mar. 1946.

2. ANTONOV, A.N. Children born during the siege of Leningrad in 1942. J. Pediatr., 30: 25 0, 1947.

3. BOULANGER PILET, M. Poids et taille des écoliers parisiens en 1938 et en 1944. Press Med., 26: 35 7-8, juin 1945.

4. LESER, W. A mortalidade infantil no período de 1950 a 1970 ; influência de fatores demográficos, sócio-econômicos $\mathrm{e}$ ambientais no nível de saúde. In: Problemas Brasileiros, out. 1984.

5. STEIN, Z. et alli. Prenatal famine effects of body size in famine and human development; the Dutch Hunger Winter of 1944-45. London, Oxford University Press, 1975.

Os autores procuram reunir evidências de diversas procedências que contribuíssem para a validação de suas teses enumeradas como títulos dos principais capítulos do texto:

- A fome é um problema bem documentado;
Paulo Sabroza - Escola Nacional de Saúde Pública FIOCRUZ - RJ 
"The data we have discussed on poverty, malnutrition and ill health is not always easy to assess. There are gaps we would like to fill and relationship that we can only guess at rather than prove. Lack of baselines data for many problems make it hard to point trends over time".

"No official "Hunger Count" exists in the U.S., so we have no precise way of knowing how many hungry people there are".

"The studies and survey.data reviewed in the previous chapter established beyound doubt that

hunger has become a serious problem again in America. The varied nature of the evidences makes it all the more compelling".

"That they felt the need to offer proof in light to substantial evidence of hunger throughout the nation is a mesure of the in tractability of the problem, on the desire of some political leaders to ignore rather than address it".
- A fome está aumentando na América;

- Desnutrição, doença e fome;

- Fome como resultado da política de governo.

Trabalharam com a revisão dos resultados de outros autores, com relatórios de documentos oficiais e coletaram informações através de um Grupo de Trabalho constituído em 1984.

Este Grupo de Trabalho multiprofissional preocupou-se em obter dados que apoiassem as teses, complementando as informações disponíveis principalmente através da construção de indicadores indire tos, como a demanda crescente aos programas de suplementação alimentar destinados ao atendimento dos pobres e entrevistas com os profissionais envolvidos, com os usuários e com indivíduos dos grupos de risco, aqueles mais pobres da população.

Mostraram que a oferta crescente não era suficiente para atender a uma demanda que aumentara muito rapidamente.

Além dos problemas conceituais da definição de fome como objeto do estudo, ressalta a insuficiência de dados registrados sistematicamente que permitissem estabelecer as tendências nos períodos estudados, refletindo a falta da prioridade que a questão vem recebendo.

A colocação do problema é objetivo principal do estado e já o justifica.

O Grupo de Trabalho não se prendeu a roteiro de entrevista, nem a procedimento definido para a seleção dos indivíduos incluídos no estudo.

A principal questão que se coloca é se as conclusões inferidas são válidas ou estão prejudicadas pela insuficiência e pouca sistematização do material disponível.

Constatou-se a concordância dos resultados de diferentes abordagens do problema, todos mostrando a presença e o aumento da fome no período estudado.

Pode-se notar que as evidências acumuladas foram todas favoráveis às teses, trazendo a questão dos critérios utilizados na sua seleção.

Um conjunto organizado de argumentos, coerentes e reforçados pela experiência do senso comum, tem grande probabilidade de ser aceito como explicação.

$\mathrm{O}$ abandono da pseudoneutralidade e a opção por um posicionamento compromissado e explícito não comprometem a validade do trabalho, ao contrário, os inserem no interior do debate da questão. Mas remetem suas conclusões ao confronto com as argumentações contrárias que foram deixadas aos pesquisadores com visão de mundo e compromissos diferentes daqueles dos autores.

No con tex to do compromisso, o trabalho não aprofunda suficientemente a análise dos determinantes da fome como 
problema social, situando-os nos limites dos programas assistenciais.

As referências limitadas aos indicadores dos países subdesenvolvidos deixam de apontar que os mesmos fatores que determinam a fome nos EUA levam a condições de vida nestes países que fazem com que a fome passe a ser mensurada objetivamente pela mortalidade específica.

\section{ALGUMAS NOTAS EM ESCALA}

(Dó) A iniciativa de um grupo-tarefa de médicos da Harvard University (School of Public Health), liderados por J.L. Brown, de realizar uma pesquisa sobre as atuais condições nutricionais e, por extensão, de saúde da população dos EUA, além de se constituir numa análise de uma conjuntura marcada pelos negativos efeitos da reaganomics sobre parcela expressiva da população americana, é também um subsídio às análises que, em perspectiva histórica, se voltam para a dinâmica do capitalismo.

(Ré) No plano da análise conjuntural, as principais conclusões da pesquisa referem-se ao caráter endêmico da fome que agora não restringiria sua presença a tradicionais "bolsões de pobreza", mas que se faria presente na vida de 20 milhões de cidadãos norte-americanos. $\mathrm{O}$ agravamento das condições nutricionais e, por extensão, das condições de saúde é correlacionado, nessa análise, a fatores como: fragilidade da rede assistencial, impacto da recessão e seus inevitáveis corolários de maior pobreza e desemprego, cortes nos programas sociais do governo oriundos de uma política orçamentário-fiscal fortemente contracionista, incapacidade da política anti-inflacionária adotada em atenuar os impactos negativos da erosão salarial e do nível de desemprego. Estes fatores derivam fundamentalmente da orientação da política econômica e social do governo Reagan - inspirada pela conhecida reaganomics - que, visando restaurar a salubridade econômico-financeira do capitalismo ameriçano, substitui o anterior "Welfare State" pelo atual "Warfare State", com inevitável piora na salubridade da população norte-americana.

(Mi) James O'Connor, em seu livro de 1973 "The fiscal crisis of the State", - aqui publicado sob o título "USA: a crise do Estado Capitalista", pela Editora Paz e Terra, em 1977 - já apontava a profundidade e gravidade da crise do "Welfare State" americano antes mesmo das sucessivas e extensas derrotas políticas do Partido Democrata, que nos EUA sempre esteve, em maior ou menor grau, comprometido com o projeto de um Estado atento às questões sociais. A raiz da crise fiscal do Estado americano está na socializa-
"American system of aid to its more vulnerable citizen has fundamentals flaws. In comparison to others industrialized nations of the world, we do not provide adequate margin of safety and security".

George E.M. Kornis

Instituto de Medicina Social Universidade do Estado do Rio de Janeiro (IMS/UERJ) 
ção dos custos da expansão do setor política e economicamente dominante - o setor monopolista - sem qualquer socialização de seus imensos lucros. O Estado americano, sob grave déficit fiscal, não logra mais absorver os custos da prosperidade e harmonia da "paz americana" pós-2a Grande Guerra. Noutros termos, quando o financiamento dos custos crescentes do Estado pela via inflacionária passa a corroer o poder de competição das empresas norte-americanas no exterior e a intensificar os conflitos sociais, ao retirar poder aquisitivo das massas marginalizadas, rompem-se as possibilidades de continuidade deste padrão de crescimento. Na análise de O'Connor, a crise fiscal e a inflação não derivam de nenhuma espécie de ineficiência da máquina administrativa estatal, da estrutura tributária, do controle orçamentário, mas sim da crescente absorção pelo Estado dos problemas do setor monopolista da economia. Assim, a crise fiscal constituia-se na caracterização da crise social nos EUA pré-Reagan. Não' deve, portanto, surpreender que uma política econômica orientada por padrões analíticos tão diversos das análises de O'Connor tenha investido tão intensamente no corte dos programas sociais do governo. Estes cortes, que integram uma política orçamentário-fiscal fortemente contracionista, constituem-se hoje na possibilidade de, ao buscar eliminar o déficit público, desonerar o Estado de qualquer embaraço no desempenho de seu papel de complemento à expansão do setor monopolista. Na perspectiva da política econômica do governo Reagan, a questão básica é a retomada da expansão da economia americana sob a liderança do setor monopolista e não a atenuação dos custos sociais desta desejada "corrida para o ouro".

(Fá) James O'Connor é um dos raros autores da URPE (Union for Radical Political Economics) publicados no Brasil. O desconhecimento no Brasil da produção intelectual deste importante segmento da esquerda não-ortodoxa é, como não poderia deixar de ser, bastante amplo. Já em 1977 a revista da URPE (The Review of Radical Political Economics, vol. 9 n? 1, spring 1977) publicava uma coletânea de artigos sobre a "Economia Política da Saúde" que, embora não refletissem diretamente sobre a fome atual nos EUA, já apontavam para os fatores sócio-econômicos e políticos que tornariam essa fome endêmica. Além deste caráter antecipatório da produção da URPE, deve-se ter claro que nestas análises não cabem nem o assistencialismo, nem o "legalismo" que tão fundamentalmente marcam as proposições politicamente ingênuas dessa força-tarefa de médicos da Harvard University (School of Public Health).

(Sol) A reflexão em torno do significado desses $20 \mathrm{mi}$ lhões de famintos cidadãos da mais rica nação do mundo não se esgota ao nível das questões conjunturais. Ela deve 
necessariamente contemplar questões de perspectiva temporal mais ampla, tais como avaliar o impacto da 3a Revolução Industrial ora em curso sobre essa legião de excluídos. A questão da fome, agora endêmica nos EUA, deve ser pensada não só no quadro de uma repartição crescentemente desigual dos frutos do progresso técnico, mas também no quadro de um processo de desagregação social ao qual o desenvolvimento do capitalismo não está infenso.

(Lá) E o Brasil, com seus milhões de famintos? Antes de mais nada, é preciso retomar a produção de informações sobre os padrões nutricionais do país, pois os dados e análises existentes são anteriores à longa provação recessiva imposta à nação pela política econômica do governo. Estas informações subsidiarão análises que não devem estar restritas a uma corporação profissional específica pois, afinal, a fome não é apenas uma questão de saúde. As análises geradas devem apoiar, técnica e politicamente, as ações que visam a conferir à alimentação um caráter de efetiva prioridade na Nova República.

(Si) Em seus recentes pronunciamentos relativos à política econômica da Nova República, o Ministro do Planejamento, Dr. João Sayad, não tem deixado dúvidas quanto à importância estratégica das prioridades sociais do governo Sarney. Estas prioridades sociais contemplariam, além das áreas de segurança pública e educação, as áreas de saúde e de alimentação. Nestas duas últimas áreas, seria conferida uma especial atenção aos programas de saneamento básico - que teriam, a partir das obras de construção civil, um impacto positivo sobre o nível de emprego e de alimentação, através do Instituto Nacional de Alimentação e Nutrição (INAN), e da merenda escolar. A efetivação desta prioridade demandará recursos que serão, infelizmente, insuficientes para resgatar a dívida social da Nação para com seus milhões de excluídos. Entretanto, com os recursos possíveis neste quadro de crise econômico-social sem precedentes na história recente do país, deve a Nação empenhar-se, profunda e energicamente, na transformação destes excluídos em cidadãos, pois estes são os elementos constitutivos básicos de uma sociedade democrática. 